\title{
Correction to: A New Kaiser-Bessel Constant Modulus Technique for Smart Antenna Beamforming
}

K. S. Shashidhara, Veerendra Dakulagi, Jasmineeth Kaur, Kim Ho Yeap, Mandeep Singh, and Ratneshwar Kumar Ratnesh

Correction to:

Chapter "A New Kaiser-Bessel Constant Modulus

Technique for Smart Antenna Beamforming" in:

N. R. Shetty et al. (eds.), Emerging Research in Computing, Information, Communication and Applications, Lecture Notes in Electrical Engineering 790, https://doi.org/10.1007/978-981-16-1342-5_56

The Chapter 56 was inadvertently published with the following belated correction. In the affiliation of co-author "Ratneshwar Kumar Ratnesh", the department has been changed from "Department of Applied Physics" to "Department of Electronics and Communication Engineering". The Correction chapter has been updated with this change. 